OPEN ACCESS

Edited by:

Giovanni Li Volti,

University of Catania, Italy

Reviewed by:

Michele Reibaldi,

University of Catania, Italy

Luisa Lanfrancone,

Istituto Europeo di Oncologia, Italy

*Correspondence:

Pedro Grachinski Buiar

pgbuiar@gmail.com

Specialty section:

This article was submitted to Molecular and Cellular Oncology,

a section of the journal

Frontiers in Oncology

Received: 15 February 2017

Accepted: 01 May 2017

Published: 18 May 2017

Citation:

Buiar PG and Azevedo SJ (2017)

Atypical Presentation: Metastatic

Uveal Melanoma in a Young Patient without Visual Complaints.

Front. Oncol. 7:99.

doi: 10.3389/fonc.2017.00099

\section{Atypical Presentation: Metastatic Uveal Melanoma in a Young Patient without Visual Complaints}

\author{
Pedro Grachinski Buiar* and Sérgio Jobim de Azevedo \\ Department of Medical Oncology, Hospital de Clínicas de Porto Alegre, Porto Alegre, Brazil
}

Background: Uveal melanoma is a rare and aggressive subtype of melanoma, with singular characteristics that separate it from the most famous cutaneous melanoma. This uncommon condition becomes even rarer if we look at young population. Common chemotherapy regimens does not work with this aggressive disease in its metastatic scenario, and the new armament like targeted and immunotherapies are still looking for more robust evidence.

Case presentation: We report a rare case of uveal melanoma in a patient younger than 20 years, with abdominal pain as his initial complaint. He did not present the typical visual symptoms of the primary site because of an auto accident suffered 4 months before the presentation, letting him blind of the eye affected by the tumor development.

Conclusion: There is always a possibility of the diagnosis of uveal melanoma in cases with associated isolated hepatic metastases, even in a young population, where this hypothesis is often rejected by the epidemiological frequency of other tumors. This rare case is a useful example.

Keywords: uveal, melanoma, metastasis, young, atypical

\section{INTRODUCTION-CASE PRESENTATION}

A healthy 17-year-old male Caucasian presented to emergency department because of vomiting (1-2 episodes per day, not preceded by nausea) associated with epigastric pain and feeling of gastric fullness for 2 weeks. He also reported sudden weight loss of $3.5 \mathrm{~kg}$ during this period, noted after onset of vomiting. He had an normal appetite, no fever, or no other concomitant symptoms. Intact Bowel and urinary habits. He was on no chronic medications or drugs and had not yet started sexual activity. He lived on the rural zone, with adequate sanitary conditions, working with farm animals (pigs and chickens) since childhood and exposing himself to solar radiation daily without regular protection. He had no contact with his biological mother (for unknown reasons). His immunization schedule was unknown too. There was no significant disease history in his biological family. As a personal history, he had cranial trauma due to car accident approximately 4 months before the presentation, resulting in multiple facial skin lacerations, associated with orbital fracture, right cornea, and anterior chamber of right eye injuries. This trauma resulted in total vision loss in the right eye. The radiological images taken in the emergency hospital during this event were lost by the patient and family.

At physical examination, the patient was pale, non-cyanotic, non-icteric, and eupneic. Scars all over the face and conjunctival hyperemia were associated with asymmetric pupillary 
deformation of the blinded right eye. There were no peripheral lymphadenopathy and no increase or change in thyroid level. Cardiopulmonary examination was normal. Abdominal distention due to massive hepatomegaly, extending through almost the entire abdominal cavity, with irregular nodulated surface was found. Palpable spleen $4 \mathrm{~cm}$ below left costal margin was seen. Testicles were normal to the examination. His skin was evaluated by a dermatologist team, without suspected injuries among a great deal of nevi.

Abdomen ultrasonography confirmed hepatomegaly with diffusely heterogeneous echogenicity at the expense of innumerable low echogenic nodules, compromising the hepatic parenchyma diffusely, reaching up to $7.1 \mathrm{~cm}$. Ascitic fluid was present in a small amount.

\section{Laboratory Tests}

The laboratory test results were as follows: hemoglobin, $13.1 \mathrm{mg} / \mathrm{dL}$; leukocyte count, 4,960 cells/ $\mu \mathrm{L}$ (normal series); platelets, $171 \times 10^{3} / \mu \mathrm{L}$; prothrombin time-INR, $1.3(14.2 \mathrm{~s})$; activated partial thromboplastin time, $38 \mathrm{~s}$; urea, $32 \mathrm{mg} / \mathrm{dL}$; creatinine, $1,12 \mathrm{mg} / \mathrm{dL}$; alanine aminotransferase, $67 \mathrm{IU} / \mathrm{L}$; aspartate aminotransferase, $62 \mathrm{IU} / \mathrm{L}$; sodium, $138 \mathrm{mEq} / \mathrm{L}$; potassium, $4.5 \mathrm{mEq} / \mathrm{L}$; lipase, $19 \mathrm{U} / \mathrm{L}$; glucose, $125 \mathrm{~g} / \mathrm{dL}$; albumin, $3.2 \mathrm{~g} / \mathrm{dL}$; alkaline phosphatase, $426 \mathrm{IU} / \mathrm{L}$; gamaglutamil transferase, $324 \mathrm{IU} / \mathrm{L}$; lactate dehydrogenase, 1,620 IU/L; total bilirubin, $0.32 \mathrm{mg} / \mathrm{dL}$; alpha-fetoprotein, $0.86 \mathrm{ng} / \mathrm{mL}$; human chorionic gonadotropin, $0,8 \mathrm{mlU} / \mathrm{mL}$; and negative serologies for Chagas disease, hepatitis, human immunodeficiency virus, cytomegalovirus, Epstein-Barr virus, and toxoplasmosis.

Abdominal CT scan (Figures 1 and 2) showed slight peripheral impregnation by contrast in the innumerous hypodense lesions, in addition to lymph node enlargement in the upper abdomen and pelvis. Low to moderate amount of free fluid was seen in the abdominal cavity. Besides all this complementary investigation, the patient initiate to complain about right eye pain, the blinded eye traumatized 4 months ago.

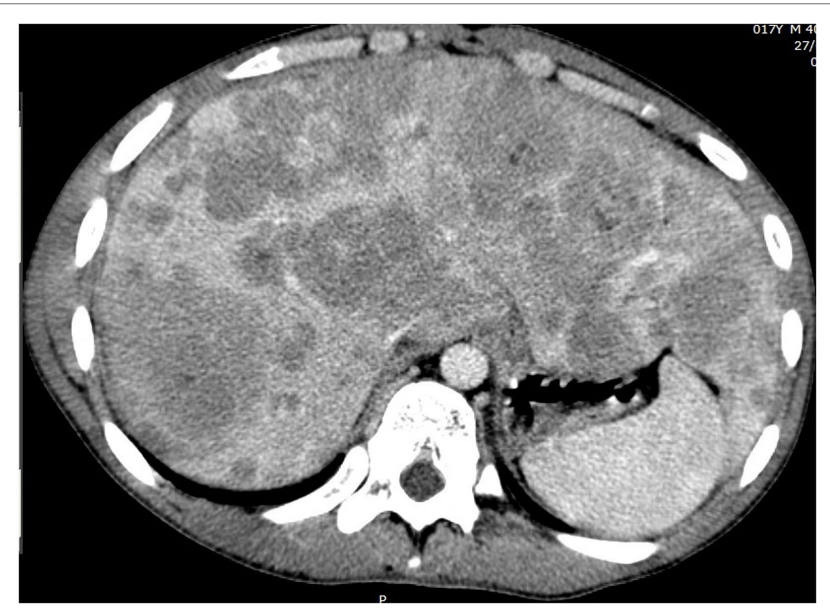

FIGURE 1 | Abdominal CT with the multiple liver metastasis.
The funduscopic examination of the right eye revealed a choroidal detachment and was not possible to define the etiology, probably traumatic. Orbit tomography (Figure 3) demonstrated right exophthalmos associated with a spontaneously expansive lesion without significant contrast enhancement, with the center located in the posterior chamber of the right eye, measuring approximately $3.0 \times 2.6 \mathrm{~cm}$ (anteroposterior $\times$ transverse).

During this investigation, the hepatic biopsy showed poorly differentiated neoplasm of polygonal cells of intermediate size, anisocariosis, and oval nucleus exhibiting evident nucleolus. Rare neoplastic cells appear to exhibit dark-to-black cytoplasmic brown pigment. Immunohistochemistry assay revealed melanomacompatible pattern: [PS100 (anti-humanS-100):positive/HMB45 (cloneHMB45):positive focal/Melan-A (cloneA103) positive].

During the entire hospitalization, patient remained with the complaint of only nausea and vomiting. Fungal lesions initially presented throughout the dorsum improved after topical treatment. Despite antiemetic measures, patient showed worsening complaints of nausea and vomiting, with abdominal pain initiating in this context. Due to the symptomatic picture, low effectiveness in this scenario and unavailability for the promptly start of immunotherapy in our public health system, we decided

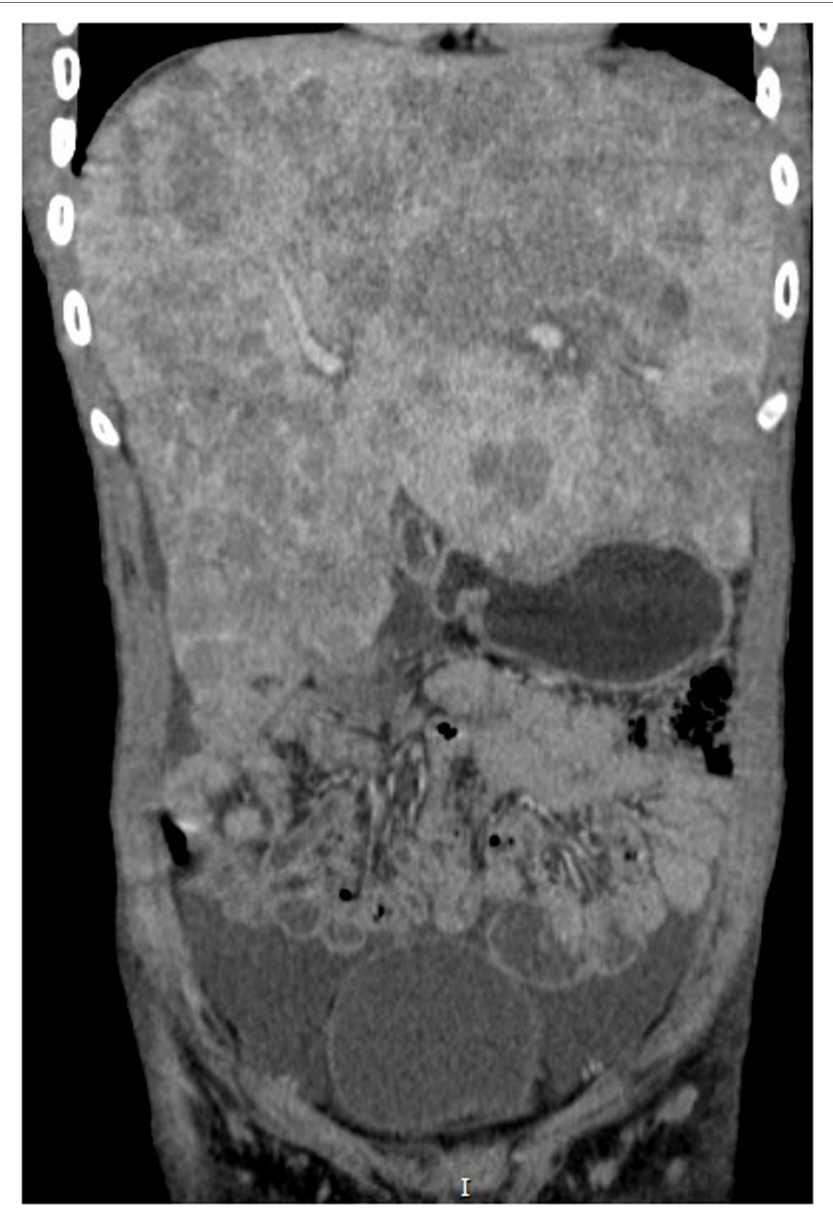

FIGURE 2 | Abdominal CT in coronal cut showing the massive hepatomegaly. 


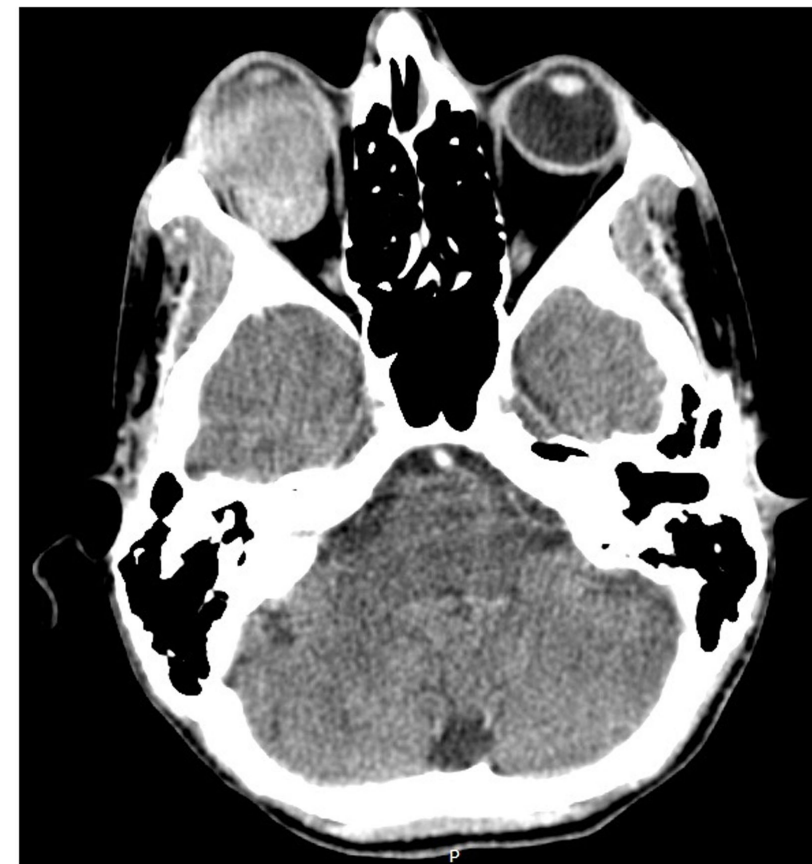

FIGURE 3 | Orbital CT with the expansive lesion in the right eye.

to initiate carboplatin and paclitaxel chemotherapy adjusted for renal and hepatic function. However, the patient developed fulminant hepatic failure in less than $24 \mathrm{~h}$ after the cytotoxic administration, presenting with encephalopathy, abrupt coagulation disorders, increased liver enzymes to $>1,000 \mathrm{IU} / \mathrm{L}$. Palliative analgesia was initiated, and the patient died within $48 \mathrm{~h}$.

\section{BACKGROUND}

\section{Epidemiology}

Uveal melanoma is a relatively rare malignancy, accounting for approximately 5.1 million cases/year (1). The uveal tract is composed of iris, ciliary body, and choroid, with uveal melanoma developing in any of these parts, after mutations in the melanocytes of this layer. Approximately $95 \%$ of ocular melanomas are found on the uvea and the remainder on the conjunctiva. This tumor variant has significant differences in relation to cutaneous melanoma, in terms of pathophysiology, prognosis, and epidemiology. The mean age at diagnosis is 60 years $(1,2)$, being rare among young patients. According to the data available in the literature, $0.5-1.3 \%$ of patients with uveal melanoma are younger than 20 years (3-5), as is the case in question. When compared with elderly patients, the younger ones are still less likely to present with metastatic disease (1). Uveal melanoma mainly affects the white population, mainly of high latitudes (6), and the proportion of whites:blacks reaches up to 196:1 in some analysis (1). Individual characteristics such as inability to tan, light skin, blue eyes, and sunburn represent risk factors associated with a higher incidence of uveal melanoma (7). Choroidal nevi are a present alteration in up to $3 \%$ of people older than
30 years (8) and are a risk factor well related to the appearance of uveal melanomas (9).

\section{Pathophysiology}

The pathogenesis of this variant of melanoma differs from the cutaneous form in some aspects, being much less studied until now. It is known that uveal melanoma does not have a high frequency of $B R A F$ mutations. By contrast, mutations in GNAQ or GNA11 (G protein subunit coders) are expressed in about $80 \%$ of the cases, being responsible by the cascade of MAPK pathway activation (10-12).

Genetic determinant prognostic changes include mutations of BRCA1-associated protein-present in $84 \%$ of metastatic cases (13). A good prognosis has been associated with mutations in the SF3B1 gene, present in $18.6 \%$ of primary uveal melanomas (14). Among clinical risk factors, the studies indicated skin phenotype, predisposition to sunburn, and clear eyes (7). Chronic ultraviolet exposure associated with activities such as welding increases the risk of uveal melanoma development (15). Choroidal nevi also are correlated with a risk of malignant transformation according to ophthalmologic measuring parameters.

\section{DISCUSSION}

\section{Diagnosis}

Intraocular tumors usually presents with visual complaints. Patients seek the ophthalmologist or general practitioner referring blurred vision, photopsia, visual scotomas, and even amaurosis. The diagnosis is based on the funduscopic examination performed by an experienced ophthalmologist, the most accurate factor for diagnosis of this condition. Biopsy is generally not necessary, and ocular globe ultrasonography is the most important complementary modality, usually eliminating the need for an invasive diagnosis. Pathologic analysis is reserved for diagnostic dilemmas, where it can drastically change the case's subsequent management (16). In differential diagnosis, primary tumors of other sites with potential to send metastasis to the uvea, such as lung and breast, should be considered $(17,18)$. Regarding staging, TNM system is classically employed (19). The risk of developing metastasis increases with the size of the primary tumor at diagnosis, as well as the probability of death within 10 years (20).

\section{Treatment of Initial Disease}

Radiotherapy achieves local tumor control in most cases, when compared to survival-related outcomes achieved by enucleation (21-24). This can be performed by brachytherapy or external field radiation. In the light of current evidence, enucleation therapy is now reserved for patients with extensive tumors and/ or local complications. There also appears to be no benefit in preenucleation radiotherapy (25). Other techniques used in the management of uveal melanoma include localized resection, transpupillary thermotherapy, photodynamic therapy, and photocoagulation.

Although local treatment is effective in preventing local recurrence in approximately $95 \%$ of cases, approximately $50 \%$ of patients develop distant metastasis within 5 years after enucleation (26). 
When treated with ocular globe irradiation, the subsequent onset of metastasis reaches $23-50 \%$, depending on prognostic factors involved $(27,28)$, i.e., increased tumor diameter, extrascleral extension, ciliary body involvement, advanced age, iris color, tumor pigmentation, symptomatic disease, and chromosomal monosomy 3 (28-39). Adjuvant therapy has no defined role, and some of the scanty evidence even brought negative results with adjuvancy, such as the study by Lane et al. (40).

Uveal melanoma spreads essentially by hematogenic path, due to the absence of lymphatic drainage in the uveal tract. Unlike cutaneous melanoma, the most common site of systemic dissemination is the liver, present in up to $90 \%$ of cases, as exemplified by our case. Genetic inheritance, histological grade, primary lesion size, and ciliary body involvement are some of the factors that increase the risk for systemic disease $(28,41)$. In the presence of such factors, and even in the absence of these factors, some experts advocate long-term follow-up because of the possibility of late metastasis arising in the disease (42). The prognosis in patients detected with metastatic disease becomes poorly, varying between 2 and 12 months for median survival in the literature $(43,44)$. Treatment of metastatic disease remained disappointing till recent years. Up to $80 \%$ of patients are dead after 1 year of diagnosis of metastasis and $90 \%$ in 2 years, with an average survival time of less than 6 months (45).

The role of systemic chemotherapy shows non-convincing benefits for cases of uveal melanoma. Therefore, the early detection of late metastasis does not have an impact on the survival of these patients due to the scarcity of treatments for the disseminated disease (46).

\section{Treatment of Metastatic Disease}

There is no therapeutic consensus for those patients who develop metastasis. Despite the use for cutaneous melanoma, the results of the most varied chemotherapy schemes and drugs were not shown to be encouraging with drugs such as dacarbazine, cisplatin, temozolomide, treosulfan, and others in the most varied combinations.

\section{Anti-CTLA4 Antibody}

Ipilimumab was evaluated by the Spanish Melanoma Group in 32 patients with treatment-naive metastatic disease. After 5.5 months, of the 13 patients available for evaluation, only 1 had partial response and 6 had stable disease. Mean overall survival in this study was 9.8 months (47). Another phase II study involved 45 previously treated patients and 8 virgin patients with metastatic uveal melanoma, performed by Zimmer and colleagues (48). Of these, six patients maintained stable disease, while none experienced any response at any level. Overall median survival of the study was 6.8 months, and median time to progression was 2.8 months. A study carried out by Maio et al. with 82 patients achieved PFS of 3.6 months, but with overall survival of 6.0 months (49). A study published in 2013 by Luke et al. (50) was able to demonstrate sustained response rates with the use of ipilimumab in this setting, at the expense of higher rates of longterm manageable adverse events. The response rate at 12 weeks was only $2.6 \%$, reaching $46 \%$ when we added the stable disease tax. At 23 weeks, this response decreased to $28.2 \%$ of cases.
The median survival in this study was 9.6 months $(95 \% \mathrm{CI}$ 6.3-13.4), summing better results for this scenario.

More recently, tremelimumab (another fully humanized anti-CTLA-4 antibody) had a study with its evaluation of efficacy terminated early due to futility after presenting a 2.9-month PFS (corresponding to $9.1 \%$ PFS rate in 6 months) (51).

\section{Anti-PD-1 and Anti-PD-L1 Therapy}

Pembrolizumab, an anti-PD1 antibody, was evaluated in a small number of patients (10 in total) in the study by Kottschade et al. (52). In this series of cases, the median PFS was 4.5 months, reaching one complete response case, two cases of partial response, and one patient with stable disease among eight evaluated at the end of follow-up. The most robust results involving modern immunotherapy in uveal melanoma come from the collection by Algazi et al. (53), involving 48 patients exposed to previous chemotherapy and 35 patients already exposed to ipilimumab who received immunotherapy with pembrolizumab (38 patients), nivolumab (16 patients), and atezolizumab (2 patients). Objective tumor response was achieved in only two patients (overall response rate $3.6 \%$ ) and stable disease in 5 patients (9\%). In this study, overall survival was 7.6 months (95\% CI 0.7-14.6 months) and PFS was 2.6 months (95\% CI 2.4-2.8 months).

\section{Molecular Target Agents}

Although uveal melanoma does not express direct changes in the $B R A F$ gene (rendering its indication of vemurafenib and dabrafenib unfeasible), it has mutations in the GNAQ or GNA11 (G protein subunit encoding) genes within $80 \%$ of cases. This lead to the activation of the cascade of MAP kinases also resulting in proliferation and tumor growth. A phase II trial conducted by Carvajal et al. (54) randomized 101 patients to compare selumetinib ( $M E K$ inhibitor) vs temozolomide with dacarbazine upfront. The progression-free survival period was substantially increased in the selumetinib arm (15.9 vs 7 weeks: HR 0.46, 95\% CI 0.3-0.71). The objective response rate was also favorable (14 vs $0 \%$ ), and although not statistically significant, median overall survival was increased (11.8 vs 9.1 months; HR $0.66,95 \%$ CI $0.41-1.06, p=0.09)$. However, the subsequent phase III study, SUMIT (55), which sought to access the efficacy of selumetinib + dacarbazine vs placebo + dacarbazine in the first-line treatment of metastatic uveal melanoma, failed to reach the primary endpoint, i.e., PFS (2.8 vs 1.8 months; HR 0.78 , 95\% CI $0.48-1.27, p=0.32$ ) in an evaluation performed by the independent review center of the study.

Other studies comparing and associating inhibition of the $M A P K$ pathway with other chemotherapeutic agents are underway. Another inhibitor of the MEK family, trametinib, was under evaluation in a phase I study (56) but demonstrated limited clinical efficacy against previously treated metastatic uveal melanomas (PFS of 1.8 months and global response rates of approximately $0 \%$ ). Another possibility that arises is the association of MEK and AKT double inhibition (whose phosphorylation is observed in $>50 \%$ of uveal melanomas). This strategy is currently being evaluated in more than one study. GNAQ and GNA11 lead mutations generate an upregulation of MET factor (related to the appearance of liver metastasis by uveal melanoma). A subgroup analysis of 23 
patients treated with cabozantinib (non-selective dual inhibitor of MET and VEGF) as part of a phase II trial (57) revealed an overall survival of 12.6 months and a PFS of 4.8 months. This led to the development of a specific phase II trial for the uveal subtype of melanoma.

\section{CONCLUDING REMARKS}

We report this case because of the rarity of metastatic uveal melanoma presentation in a 17 -year-old patient. The unfortunate fact of this advanced and very rapid presentation could have as a contributor the missed diagnosis of the primary tumor due to the absence of visual symptoms caused by a previous local trauma. Most likely, this lesion was already developing at the time of the trauma, not being detected at the time of the medical evaluation or being confused with trauma artifacts, most likely with hepatic implants already in development 4 months earlier. The highspeed unfavorable evolution of this case was determined by an advanced liver involvement.

\section{REFERENCES}

1. Singh AD, Turell ME, Topham AK. Uveal melanoma: trends in incidence, treatment, and survival. Ophthalmology (2011) 118:1881-5. doi:10.1016/j. ophtha.2011.01.040

2. Chang AE, Karnell LH, Menck HR. The National Cancer Data Base report on cutaneous and noncutaneous melanoma: a summary of 84,836 cases from the past decade. The American College of Surgeons Commission on Cancer and the American Cancer Society. Cancer (1998) 83:1664-78. doi:10.1002/ (SICI)1097-0142(19981015)83:8<1664::AID-CNCR23>3.0.CO;2-G

3. Shields CL, Kaliki S, Furuta M, Mashayekhi A, Shields JA. Clinical spectrum and prognosis of uveal melanoma based on age at presentation in 8,033 cases. Retina (2012) 32(7):1363-72. doi:10.1097/IAE.0b013e31824d09a8

4. Singh AD, Shields CL, Shields JA, Sato T. Uveal melanoma in young patients. Arch Ophthalmol (2000) 118:918-23. doi:10-1001/pubs.Ophthalmol

5. Vavvas D, Kim I, Lane AM, Chaglassian A, Mukai S, Gragoudas E. Posterior uveal melanoma in young patients treated with proton beam therapy. Retina (2010) 30:1267-71. doi:10.1097/IAE.0b013e3181cfdfad

6. Seddon JM, Gragoudas ES, Glynn RJ, Egan KM, Albert DM, Blitzer PH. Host factors, UV radiation, and risk of uveal melanoma. A case-control study. Arch Ophthalmol (1990) 108:1274-80. doi:10.1001/archopht.1990.01070110090031

7. Weis E, Shah CP, Lajous M, Shields JA, Shields CL. The association between host susceptibility factors and uveal melanoma: a meta-analysis. Arch Ophthalmol (2006) 124:54-60. doi:10.1001/archopht.124.1.54

8. Ganley JP, Comstock GW. Benign nevi and malignant melanomas of the choroid. Am J Ophthalmol (1973) 76:19-25. doi:10.1016/0002-9394(73)90003-2

9. Grob JJ, Gouvernet J, Aymar D, Mostaque A, Romano MH, Collet AM, et al. Count of benign melanocytic nevi as a major indicator of risk for nonfamilial nodular and superficial spreading melanoma. Cancer (1990) 66:387-95. doi:10.1002/ 1097-0142(19900715)66:2<387::AID-CNCR2820660232>3.0.CO;2-J

10. Van Raamsdonk CD, Griewank KG, Crosby MB, Garrido MC, Vemula S, Wiesner T, et al. Mutations in GNA11 in uveal melanoma. N Engl J Med (2010) 363:2191. doi:10.1056/NEJMoa1000584

11. Van Raamsdonk CD, Bezrookove V, Green G, Bauer J, Gaugler L, O’Brien JM, et al. Frequent somatic mutations of GNAQ in uveal melanoma and blue naevi. Nature (2009) 457:599. doi:10.1038/nature07586

12. Onken MD, Worley LA, Long MD, Duan S, Council ML, Bowcock AM, et al. Oncogenic mutations in GNAQ occur early in uveal melanoma. Invest Ophthalmol Vis Sci (2008) 49:5230. doi:10.1167/iovs.08-2145

13. Harbour JW, Onken MD, Roberson ED, Duan S, Cao L, Worley LA, et al. Frequent mutation of BAP1 in metastasizing uveal melanomas. Science (2010) 330:1410. doi:10.1126/science.1194472
We emphasize the importance of ocular examination and the consideration of uveal melanoma in the differential diagnosis of cases with metastatic neoplasia without defined primary focus, even at early ages, and especially when presenting isolated liver metastasis. This report serves as an alert for pediatricians and other oncologists to the fact that there is a very rare but possible presence of uveal melanoma in the youth.

\section{ETHICS STATEMENT}

The patient and his legal representatives signed a consensus agreement authorizing the medical oncologist to use their medical records and images in the case report, preserving the patient's identity.

\section{AUTHOR CONTRIBUTIONS}

PB: physician who assisted the patient during his hospitalization and was responsible for compiling data. SA: medical advisor.

14. Gupta MP, Lane AM, DeAngelis MM, Mayne K, Crabtree M, Gragoudas ES, et al. Clinical characteristics of uveal melanoma in patients with germline BAP1 mutations. JAMA Ophthalmol (2015) 133:881. doi:10.1001/ jamaophthalmol.2015.1119

15. Shah CP, Weis E, Lajous M, Shields JA, Shields CL. Intermittent and chronic ultraviolet light exposure and uveal melanoma: a meta-analysis. Ophthalmology (2005) 112:1599. doi:10.1016/j.ophtha.2005.04.020

16. Augsburger JJ, Shields JA, Folberg R, Lang W, O’Hara BJ, Claricci JD. Fine needle aspiration biopsy in the diagnosis of intraocular cancer. Cytologic-histologic correlations. Ophthalmology (1985) 92:39-49. doi:10.1016/S0161-6420(85)34068-X

17. Shah SU, Mashayekhi A, Shields CL, Walia HS, Hubbard GB III, Zhang J, et al. Uveal metastasis from lung cancer: clinical features, treatment, and outcome in 194 patients. Ophthalmology (2014) 121:352. doi:10.1016/j. ophtha.2013.07.014

18. Demirci H, Shields CL, Chao AN, Shields JA. Uveal metastasis from breast cancer in 264 patients. Am JOphthalmol (2003) 136:264. doi:10.1016/ S0002-9394(03)00192-2

19. American Joint Committee. Malignant melanoma of the uvea. 7th ed. In: Edge SB, Byrd DR, Compton CC, et al., editors. American Joint Committee on Cancer Staging Manual. New York, NY: Springer (2010). 541 p.

20. Shields CL, Kaliki S, Furuta M, Fulco E, Alarcon C, Shields JA. American Joint Committee on Cancer classification of posterior uveal melanoma (tumor size category) predicts prognosis in 7731 patients. Ophthalmology (2013) 120:2066. doi:10.1016/j.ophtha.2013.03.012

21. Seddon JM, Gragoudas ES, Egan KM, Glynn RJ, Howard S, Fante RG, et al. Relative survival rates after alternative therapies for uveal melanoma. Ophthalmology (1990) 97:769. doi:10.1016/S0161-6420(90)32512-5

22. Adams KS, Abramson DH, Ellsworth RM, Haik BG, Bedford M, Packer S, et al. Cobalt plaque versus enucleation for uveal melanoma: comparison of survival rates. Br J Ophthalmol (1988) 72:494. doi:10.1136/bjo.72.7.494

23. Augsburger JJ, Corrêa ZM, Freire J, Brady LW. Long-term survival in choroidal and ciliary body melanoma after enucleation versus plaque radiation therapy. Ophthalmology (1998) 105:1670. doi:10.1016/S0161-6420(98)99037-6

24. Diener-West M, Earle JD, Fine SL, Hawkins BS, Moy CS, Reynolds SM, et al. The COMS randomized trial of iodine 125 brachytherapy for choroidal melanoma, III: initial mortality findings. COMS Report No. 18. Arch Ophthalmol (2001) 119:969. doi:10.1001/archopht.119.7.969

25. Hawkins BS, Collaborative Ocular Melanoma Study Group. The Collaborative Ocular Melanoma Study (COMS) randomized trial of pre-enucleation radiation of large choroidal melanoma: IV. Ten-year mortality findings and prognostic factors. COMS report number 24. Am J Ophthalmol (2004) 138:936. doi:10.1016/j.ajo.2004.07.006 
26. Kujala E, Mäkitie T, Kivelä T. Very long-term prognosis of patients with malignant uveal melanoma. Invest Ophthalmol Vis Sci (2003) 44:4651. doi:10.1167/ iovs.03-0538

27. Char DH, Kroll SM, Castro J. Ten-year follow-up of helium ion therapy for uveal melanoma. Am JOphthalmol (1998) 125:81. doi:10.1016/ S0002-9394(99)80238-4

28. Gragoudas E, Li W, Goitein M, Lane AM, Munzenrider JE, Egan KM. Evidencebased estimates of outcome in patients irradiated for intraocular melanoma. Arch Ophthalmol (2002) 120:1665. doi:10.1001/archopht.120.12.1665

29. Gragoudas ES, Seddon JM, Egan KM, Polivogianis L, Hsieh CC, Goitein M, et al. Prognostic factors for metastasis following proton beam irradiation of uveal melanomas. Ophthalmology (1986) 93:675. doi:10.1016/ S0161-6420(86)33699-6

30. Schmittel A, Bechrakis NE, Martus P, Mutlu D, Scheibenbogen C, Bornfeld N, et al. Independent prognostic factors for distant metastases and survival in patients with primary uveal melanoma. Eur J Cancer (2004) 40:2389. doi:10.1016/j.ejca.2004.06.028

31. Kleineidam M, Guthoff R, Bentzen SM. Rates of local control, metastasis, and overall survival in patients with posterior uveal melanomas treated with ruthenium-106 plaques. Radiother Oncol (1993) 28:148. doi:10.1016/0167-8140(93)90007-U

32. Affeldt JC, Minckler DS, Azen SP, Yeh L. Prognosis in uveal melanoma with extrascleral extension. Arch Ophthalmol (1980) 98:1975. doi:10.1001/ archopht.1980.01020040827006

33. Schmittel A, Bechrakis NE, Martus P, Mutlu D, Scheibenbogen C, Bornfeld N, et al. Prognostic factors for development of metastatic disease in ocular melanoma: 5 years follow-up of 271 patients. Proc Am Soc Clin Oncol (2003) 22:711a.

34. Sandinha MT, Farquharson MA, McKay IC, Roberts F. Monosomy 3 predicts death but not time until death in choroidal melanoma. Invest Ophthalmol Vis Sci (2005) 46:3497. doi:10.1167/iovs.05-0613

35. Kilic E, van Gils W, Lodder E, Beverloo HB, van Til ME, Mooy CM, et al. Clinical and cytogenetic analyses in uveal melanoma. Invest Ophthalmol Vis Sci (2006) 47:3703. doi:10.1167/iovs.06-0101

36. Onken MD, Worley LA, Person E, Char DH, Bowcock AM, Harbour JW. Loss of heterozygosity of chromosome 3 detected with single nucleotide polymorphisms is superior to monosomy 3 for predicting metastasis in uveal melanoma. Clin Cancer Res (2007) 13:2923. doi:10.1158/1078-0432.CCR-06-2383

37. Damato B, Duke C, Coupland SE, Hiscott P, Smith PA, Campbell I, et al. Cytogenetics of uveal melanoma: a 7-year clinical experience. Ophthalmology (2007) 114:1925. doi:10.1016/j.ophtha.2007.06.012

38. Damato B, Coupland SE. Translating uveal melanoma cytogenetics into clinical care. Arch Ophthalmol (2009) 127:423. doi:10.1001/ archophthalmol.2009.40

39. Worley LA, Onken MD, Person E, Robirds D, Branson J, Char DH, et al. Transcriptomic versus chromosomal prognostic markers and clinical outcome in uveal melanoma. Clin Cancer Res (2007) 13:1466. doi:10.1158/1078-0432. CCR-06-2401

40. Lane AM, Egan KM, Harmon D, Holbrook A, Munzenrider JE, Gragoudas ES. Adjuvant interferon therapy for patients with uveal melanoma at high risk of metastasis. Ophthalmology (2009) 116:2206. doi:10.1016/j.ophtha.2009.04.044

41. Coupland SE, Campbell I, Damato B. Routes of extraocular extension of uveal melanoma: risk factors and influence on survival probability. Ophthalmology (2008) 115:1778-85. doi:10.1016/j.ophtha.2008.04.025

42. Lane AM, Kim IK, Gragoudas ES. Long-term risk of melanoma-related mortality for patients with uveal melanoma treated with proton beam therapy. JAMA Ophthalmol (2015) 133:792. doi:10.1001/jamaophthalmol.2015.0887

43. Rietschel P, Panageas KS, Hanlon C, Patel A, Abramson DH, Chapman PB. Variates of survival in metastatic uveal melanoma. J Clin Oncol (2005) 23:8076. doi:10.1200/JCO.2005.02.6534

44. Augsburger JJ, Corrêa ZM, Shaikh AH. Effectiveness of treatments for metastatic uveal melanoma. Am J Ophthalmol (2009) 148:119. doi:10.1016/j. ajo.2009.01.023

45. Diener-West M, Reynolds SM, Agugliaro DJ, Caldwell R, Cumming K, Earle JD, et al. Development of metastatic disease after enrollment in the
COMS trials for treatment of choroidal melanoma: Collaborative Ocular Melanoma Study Group Report No. 26. Arch Ophthalmol (2005) 123:1639-43. doi:10.1001/archopht.123.12.1639

46. Gragoudas ES, Egan KM, Seddon JM, Glynn RJ, Walsh SM, Finn SM, et al. Survival of patients with metastases from uveal melanoma. Ophthalmology (1991) 98:383. doi:10.1016/S0161-6420(91)32285-1

47. Piulats Rodriguez J, Ochoa de Olza M, Codes M, Lopez-Martin JA, Berrocal A, Garcia M, et al. Phase II study evaluating ipilimumab as a single agent in the first-line treatment of adult patients (Pts) with metastatic uveal melanoma (MUM): the GEM-1 trial. J Clin Oncol (2014) 32:9033. doi:10.1200/ jco.2014.32.15

48. Zimmer L, Vaubel J, Mohr P, Hauschild A, Utikal J, Simon J, et al. Phase II DeCOG-study of ipilimumab in pretreated and treatment-naïve patients with metastatic uveal melanoma. PLoS One (2015) 10(3):e0118564. doi:10.1371/ journal.pone.0118564

49. Maio M, Danielli R, Chiarion-Sileni V, Pigozzo J, Parmiani G, Ridolfi R, et al. Efficacy and safety of ipilimumab in patients with pre-treated, uveal melanoma. Ann Oncol (2013) 24(11):2911. doi:10.1093/annonc/mdt376

50. Luke JJ, Callahan MK, Postow MA, Romano E, Ramaiya N, Bluth M, et al. Clinical activity of ipilimumab for metastatic uveal melanoma: a retrospective review of the Dana-Farber Cancer Institute, Massachusetts General Hospital, Memorial Sloan-Kettering Cancer Center, and University Hospital of Lausanne experience. Cancer (2013) 119(20):3687. doi:10.1002/ cncr. 28282

51. Joshua AM, Monzon JG, Mihalcioiu C, Hogg D, Smylie M, Cheng T. A phase 2 study of tremelimumab in patients with advanced uveal melanoma. Melanoma Res (2015) 25:342-7. doi:10.1097/CMR.0000000000000175

52. Kottschade LA, McWilliams RR, Markovic SN, Block MS, Villasboas Bisneto J, Pham AQ, et al. The use of Pembrolizumab for the treatment of metastatic uveal melanoma. Melanoma Res (2016) 26(3):300-3. doi:10.1097/ CMR.0000000000000242

53. Algazi AP, Tsai KK, Shoushtari AN, Munhoz RR, Eroglu Z, Piulats JM, et al. Clinical outcomes in metastatic uveal melanoma treated with PD-1 and PD-L1 antibodies. Cancer (2016) 122(21):3344. doi:10.1002/ cncr.30258

54. CarvajalRD,SosmanJA,QuevedoJF,Milhem MM,JoshuaAM,KudchadkarRR, et al. Effect of selumetinib vs chemotherapy on progression-free survival in uveal melanoma: a randomized clinical trial. JAMA (2014) 311(23):2397. doi:10.1001/jama.2014.6096

55. Carvajal RD, Schwartz GK, Mann H, Smith I, Nathan PD. SUMIT: Phase III, Randomized, Placebo-Controlled, Double-Blind Trial of Selumetinib in Combination with Dacarbazine in Patients with Metastatic Uveal Melanoma. San Francico, CA: Society for Melanoma Research Congress (2015).

56. Falchook GS, Lewis KD, Infante JR, Gordon MS, Vogelzang NJ, DeMarini DJ, et al. Activity of the oral MEK inhibitor trametinib in patients with advanced melanoma: a phase1 dose-escalation trial. Lancet Oncol (2012) 13:782-9. doi:10.1016/S1470-2045(12)70269-3

57. Daud A, Kluger HM, Edelman G, Gordon MS, Schimmoller F, Weitzman A, et al. Activity of cabozantinib in metastatic uveal melanoma: updated results from a phase II randomized discontinuation trial (RDT). J Clin Oncol (2013) 31(Suppl):Abstract9094. doi:10.1038/bjc.2016.419

Conflict of Interest Statement: The authors declare that the research was conducted in the absence of any commercial or financial relationships that could be construed as a potential conflict of interest.

The reviewer, MR, and handling editor declared their shared affiliation, and the handling editor states that the process nevertheless met the standards of a fair and objective review.

Copyright () 2017 Buiar and Azevedo. This is an open-access article distributed under the terms of the Creative Commons Attribution License (CC BY). The use, distribution or reproduction in other forums is permitted, provided the original author(s) or licensor are credited and that the original publication in this journal is cited, in accordance with accepted academic practice. No use, distribution or reproduction is permitted which does not comply with these terms. 